\title{
The Meissner Corpuscle Revised: A Multiafferented Mechanoreceptor with Nociceptor Immunochemical Properties
}

\author{
Michel Paré, ${ }^{1}$ Robert Elde, ${ }^{2}$ Joseph E. Mazurkiewicz, ${ }^{3}$ Allan M. Smith, ${ }^{1}$ and Frank L. Rice ${ }^{3}$ \\ ${ }^{1}$ Département de Physiologie, Université de Montréal, Montréal, Québec, Canada H3C 3J7, 2Department of \\ Neuroscience, University of Minnesota, Minneapolis, Minnesota 55455, and ${ }^{3}$ Center for Neuropharmacology and \\ Neuroscience, Albany Medical College, Albany, New York 12208
}

\begin{abstract}
Meissner corpuscles (MCs) in the glabrous skin of monkey digits have at least three types of innervation as revealed by immunofluorescence. The previously well known $A \alpha \beta$-fiber terminals are closely intertwined with endings from peptidergic C-fibers. These intertwined endings are segregated into zones that alternate with zones containing a third type of ending supplied by nonpeptidergic C-fibers. Although MCs are widely regarded as low-threshold mechanoreceptors, all three types of innervation express immunochemical properties associated with nociception. The peptidergic $\mathrm{C}$-fiber endings have readily detectable levels of immunoreactivity (IR) for calcitonin generelated peptide (CGRP) and substance $\mathrm{P}(\mathrm{SP})$. The $\mathrm{A} \alpha \beta$ endings
\end{abstract}

The glabrous skin of mammals is supplied by many primary afferents that have rapidly adapting responses within sharply defined receptive fields (Lindblom, 1965; Talbot et al., 1968; Knibestöl and Vallbo, 1970; Pubols et al., 1971; Johansson, 1978; Turnbull and Rasmusson, 1986; Proske et al., 1998). These responses are purportedly mediated through Meissner corpuscles (MCs) in rodents, marsupials, primates, and humans. MCs contain a coiled arrangement of endings from as many as six myelinated axons (Cauna, 1956; Halata, 1975) that terminate between layers of flattened Schwann cells (Munger and Ide, 1988; Guinard et al., 2000).

Interestingly, a study by Dogiel (1892) indicated that MCs in humans also contain input from small-caliber axons, and Cauna (1956) verified the presence of unmyelinated innervation by electron microscopy, but these observations have been mostly overlooked. Immunoreactivity for calcitonin gene-related peptide (CGRP) and substance P (SP) has been detected in MCs (Dalsgaard et al., 1983, 1989; Björklund et al., 1986; Ishida-Yamamoto et al., 1988) and very recently on thin-caliber intracorpuscular fibers in human MCs (Johansson et al., 1999). These observations indicate that MCs may also have nociceptive capabilities.

The present study investigated the immunofluorescent charac-

\footnotetext{
Received Oct. 17, 2000; revised June 19, 2001; accepted June 25, 2001.

This study was supported by the Albany Medical College Strategic Research Plan, by National Institutes of Health Grant NS34692 to F.L.R., and by a Canadian Institutes of Health research grant to A.M.S. We thank Marilyn Dockum and Lise Lessard for technical assistance in processing the tissue and Dr. David Julius (Department of Cellular and Molecular Pharmacology, University of California, San Francisco, CA) and Dr. Michael Caterina (Department of Biological Chemistry, Johns Hopkins University, Baltimore, MD) for providing VR1 and VRL1 antibodies.

Correspondence should be addressed to Frank L. Rice, Center for Neuropharmacology and Neuroscience, Albany Medical College, 47 New Scotland Avenue, Albany, NY 12208. E-mail: ricef@mail.amc.edu.

Copyright $\odot 2001$ Society for Neuroscience $0270-6474 / 01 / 217236-11 \$ 15.00 / 0$
}

have relatively lower levels of IR for CGRP and SP as well as the $\mathrm{SP}$ neurokinin 1 receptor and vanilloid-like receptor 1 . Both the $\mathrm{A} \alpha \beta$ and peptidergic C-fiber endings were also labeled with antibodies for different combinations of adrenergic, opioid, and purinergic receptors. The nonpeptidergic $\mathrm{C}$-fiber endings express IR for vanilloid receptor 1 , which has also been implicated in nociception. Thus, MCs are multiafferented receptor organs that may have nociceptive capabilities in addition to being low-threshold mechanoreceptors.

Key words: digit; cutaneous innervation; Meissner corpuscle; primate; mechanoreceptors; nociceptors

teristics of Meissner endings in the glabrous skin of two Old World monkeys (Macaca fascicularis and Macaca mulata) using antisera against numerous antigens, including many implicated in nociception. In addition to the previously known $\mathrm{A} \alpha \beta$-myelinated innervation, our results confirmed the presence of a CGRPpositive $\mathrm{C}$-fiber innervation and, for the first time, revealed another larger contingent of nonpeptidergic $\mathrm{C}$-fiber innervation immunoreactive for vanilloid receptor 1 (VR1). Importantly, all three types of innervation also had other immunochemical characteristics that have been implicated in nociception. Moreover, the CGRP-positive C-fiber innervation coexpressed SP immunoreactivity (IR) and was closely affiliated with the $\mathrm{A} \alpha \beta$ endings that expressed IR for the SP receptor neurokinin 1 (NK1; Gether et al., 1993). Thus, these two sets of innervation may functionally interact.

\section{MATERIALS AND METHODS}

Specimens. Glabrous skin tissue was collected from five monkeys (four $M$. fascicularis and one M. mulata). Before this study, these animals were the subject of benign tactile grasping studies. Only the data related to the immunofluorescence analyses of the glabrous skin are reported here. At the termination of behavioral studies, the monkeys were killed with an overdose of sodium pentobarbital and perfused transcardially with $0.9 \%$ saline, followed by $4 \%$ paraformaldhyde in $0.1 \mathrm{~m}$ PBS, $\mathrm{pH} 7.4$, and $4^{\circ} \mathrm{C}$ and by $4 \%$ sucrose in PBS. Immediately after perfusion, the hands were dissected and post-fixed at $4{ }^{\circ} \mathrm{C}$ in the perfusion fixative for $4 \mathrm{hr}$ or overnight, rinsed several times in PBS, and stored in $0.1 \%$ sodium azide in PBS. Sectors of skin were removed as close as possible from the underlying bone and tendons. The tissue was cryoprotected by overnight infiltration with $30 \%$ sucrose in PBS and cut by cryostat into $14 \mu \mathrm{m}$ sections perpendicular or parallel to the skin surface. The sections were thawed onto chrome-alum-gelatin-coated slides, air-dried overnight, and processed for single or double immunolabeling. Animal housing and all surgical and experimental procedures complied with the Université de Montréal Animal Care and Use Guidelines and the Society for Neuroscience.

Immunofluorescence. Immunofluorescence was assessed for several 


\begin{tabular}{|c|c|c|}
\hline Antigen & Antibody (dilution) & Source \\
\hline PGP9.5 & Rabbit polyclonal (1:800-1500) & UltraClone Ltd. (Wellow, UK) \\
\hline \multirow[t]{2}{*}{ CGRP } & Sheep polyclonal (1:800-1500) & Affiniti Research Products (Mamhead-Exeter, UK) \\
\hline & Rabbit polyclonal (1:800-1500) & Chemicon International (Temecula, CA) \\
\hline \multicolumn{3}{|l|}{ Neurofilament $200 \mathrm{kDa}$ subunit } \\
\hline Nonphosphorylated (NFn) & Rabbit polyclonal (1:800-1500) & Chemicon International \\
\hline Phosphorylated (NFp) & Mouse monoclonal (RT97) (1:400-800) & Chemicon International \\
\hline Glia-specific S100 protein & Rabbit polyclonal (prediluted) & Biogenesis (Poole, UK) \\
\hline MBP & Mouse monoclonal (1:500-1000) & Sternberger Monoclonals (Baltimore, MD) \\
\hline SP & Guinea pig polyclonal $(1: 400-800)$ & Research Diagnostics (Flanders, NJ) \\
\hline Substance P receptor (NK1) & Rabbit polyclonal (1:1000-3000) & Chemicon International \\
\hline \multicolumn{3}{|l|}{ Purinergic receptors } \\
\hline $\mathrm{P} 2 \mathrm{X} 1$ & Rabbit polyclonal (1:1000-3000) & Vulchanova et al., 1996 \\
\hline $\mathrm{P} 2 \mathrm{X} 2$ & Rabbit polyclonal (1:500-1500) & Vulchanova et al., 1996 \\
\hline $\mathrm{P} 2 \mathrm{X} 3$ & Rabbit polyclonal (1:500-1500) & Vulchanova et al., 1997 \\
\hline \multicolumn{3}{|l|}{ Opioid receptors } \\
\hline$\kappa \mathrm{OR}$ & Rabbit polyclonal (1:1000-3000) & Arvidsson et al., $1995 \mathrm{c}$ \\
\hline$\mu \mathrm{OR}$ & Rabbit polyclonal (1:1000-3000) & Arvidsson et al., 1995b \\
\hline$\delta \mathrm{OR}$ & Rabbit polyclonal (1:1000-3000) & Arvidsson et al., 1995a \\
\hline \multicolumn{3}{|l|}{ Adrenergic receptors } \\
\hline Alpha 2A $(\alpha 2 \mathrm{~A})$ & Rabbit polyclonal (1:1000-3000) & Stone et al., 1998 \\
\hline Alpha 2C $(\alpha 2 \mathrm{C})$ & Rabbit polyclonal (1:1000-3000) & Stone et al., 1998 \\
\hline \multicolumn{3}{|l|}{ Vanilloid receptors } \\
\hline VR1 & Guinea pig polyclonal (1:1000-3000) & Guo et al., 1999 \\
\hline VR1 & Rabbit polyclonal (1:1000-3000) & Guo et al., 1999 \\
\hline VR1 & Rabbit polyclonal (1:1500-5000) & Caterina et al., 1997 \\
\hline VRL1 & Rabbit polyclonal (1:1000-3000) & Caterina et al., 1999 \\
\hline NOCI & Rabbit polyclonal (1:1000-3000) & Riedl et al., 1996 \\
\hline
\end{tabular}

primary antibodies (Table 1) used in single-labeling and in doublelabeling combinations. The slides of sections were preincubated in $1 \%$ bovine serum albumin (BSA) and $0.3 \%$ Triton X-100 in PBS for $30 \mathrm{~min}$ and then incubated with primary antibody diluted in PBS containing $1 \%$ BSA and $0.3 \%$ Triton X-100 for $48 \mathrm{hr}$ in a humid atmosphere at $4^{\circ} \mathrm{C}$. Slides were then rinsed in excess PBS for $30 \mathrm{~min}$ and incubated for $2 \mathrm{hr}$ at room temperature with either Cy-2- or Cy-3-conjugated secondary antibodies (Jackson ImmunoResearch, West Grove, PA) diluted 1:250 and 1:500, respectively, in PBS containing 1\% BSA and $0.3 \%$ Triton $\mathrm{X}-100$. Afterward, the sections were rinsed for $30 \mathrm{~min}$ in PBS and either processed for a second run of primary and secondary antibodies or coverslipped under $90 \%$ glycerol in PBS.

To control for nonspecific labeling, incubations were conducted without the primary antibodies and with primary antibodies preabsorbed with their specific blocking peptide. Labeling with anti- $\alpha 2 \mathrm{~A}-\mathrm{IR}$ was substantially reduced but still persisted after preabsorption with its specific peptide, whereas all other antigen labeling was eliminated. To control for false-positive results attributable to cross-binding in double-label combinations, each primary antibody raised in a particular species was used in at least four different double-label combinations involving other primary antibodies raised in three other species. The order of the primary antibody incubations was then reversed for each double-label combination. Importantly, the double-label combinations included two primary antibodies against $200 \mathrm{kDa}$ neurofilament protein $(\mathrm{NF})$, one raised in mouse and the other in rabbit; two antibodies against CGRP, one raised in rabbit and the other in sheep; and three antibodies against VR1, two raised in rabbit and the other in guinea pig (Table 1). As will be shown in Results, these three sets of antibodies are fundamental discriminators for three types of innervation to the MCs. As such, these three sets of antibodies provided common bases for comparing double-label combinations with the other primary antibodies. All permutations of double labeling were conducted that would test for coexpression of antigens and that would control for, and rule out, nonspecific labeling on the innervation.

For each sequence of primary antibodies, the order of $\mathrm{Cy}-3-$ and
Cy-2-conjugated secondary antibodies was also reversed to control for nonspecific labeling among secondary antibodies and for any "bleeding" of $\mathrm{Cy}-3$ fluorescence through the $\mathrm{Cy}-2$ filters. No bleeding was observed. The only detectable cross-binding was anti-sheep secondary antibodies with goat secondary antibodies such as goat anti-rabbit. Consequently, only secondary antibodies raised in donkey were used in double-label combinations involving sheep primary antibodies.

Analysis. The sections were analyzed with an Olympus Optical (Tokyo, Japan) Provis AX70 microscope equipped for conventional epifluorescence (Cy-3 filters, 528-553 nm excitation and 590-650 nm emission; Cy-2 filters, $460-500 \mathrm{~nm}$ excitation and $510-560 \mathrm{~nm}$ emission). Fluorescence images were captured $(1280 \times 1024$ pixels $)$ with a high-resolution three-color CCD camera (Sony DKC-ST5) interfaced with Northern Eclipse software (Empix Imaging, Mississauga, Ontario, Canada). Images were deblurred using a deconvolution program based on a $1 \mu \mathrm{m}$ two-dimensional nearest neighbor paradigm (Empix Imaging; Carrington et al., 1995). In some cases, confocal optical sections were collected with a confocal laser scanning microscope (Nikon Diaphot 200 or Noran OZ) using a 40 or $60 \times$ objective lens. The stacks of confocal images were obtained from $0.5 \mu \mathrm{m}$ serial optical sections. The exceptionally high sensitivity of the Sony digital camera enabled capture of weak fluorescent signals with exposure times typically $<2 \mathrm{sec}$ and never $>4 \mathrm{sec}$. This enabled image capture even when fluorescence intensity was too weak to withstand the more prolonged exposure required to select sites and to set scanning parameters for confocal microscopy. Double labeling was assessed by digitally merging the captured images.

This study does not attempt to quantify the relative amounts of various labeled antigens, because the intensity of immunolabeling for the various antibodies is attributable to many variables that cannot be individually distinguished and quantified. This includes true differences in the presence and quantity of the antigen, the location of the antigen (e.g., membrane or cytosol), efficacy of the antibody, antibody concentration, background labeling, and whether the antibody is monoclonal or polyclonal. For some antibodies such as anti-CGRP and anti-protein gene product 9.5 (PGP9.5), labeling intensity will be referred to as high, 


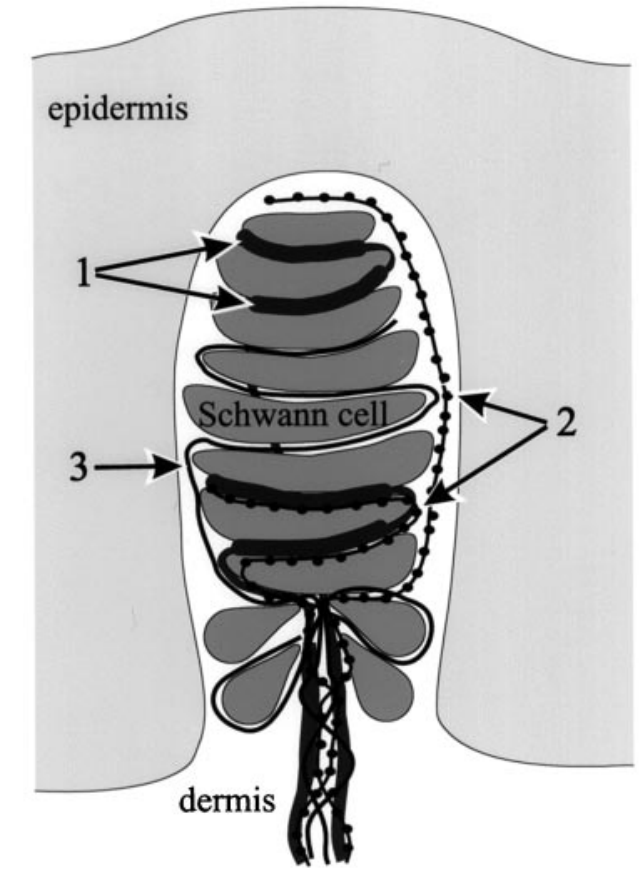

1) Myelinated afferent: NF200, MBP, CGRP, SP, NK1, 8 OR, $\alpha 2 A$, $\alpha 2 \mathrm{C}, \mathrm{P} 2 \mathrm{X} 2, \mathrm{P} 2 \mathrm{X} 3$, VRL1

2) Unmyelinated varicose afferent:. CGRP, SP, $\mu O R, \delta O R, \alpha 2 \mathrm{~A}, \mathrm{P} 2 \mathrm{X} 1, \mathrm{P} 2 \mathrm{X} 2$, $\mathrm{P} 2 \mathrm{X} 3, \mathrm{NOCI}$

\section{3) Unmyelinated nonvaricose afferent: VR1, P2X1, NOCI, $\mu O R$ ?, $\delta O R$ ?}

Figure 1. Schematic drawing of an MC shown in a plane perpendicular to the skin surface and illustrating three different types of innervation: 1, NF-positive $\mathrm{A} \alpha \beta$-fiber innervation (dark gray); 2, varicose CGRP-positive C-fiber innervation (black with dots); and 3, nonpeptidergic VR1-positive $\mathrm{C}$-fiber innervation (black). The MCs are located in dermal papillae that protrude into the epidermis. The unmyelinated CGRP-positive $\mathrm{C}$-fiber innervation is closely affiliated with the $\mathrm{A} \alpha \beta$ endings, although some distributes independently around the contour of the MC. The nonpeptidergic VR1 innervation is segregated to zones interdigitated between the intertwined $\mathrm{A} \alpha \beta$ and unmyelinated CGRP-positive C-fiber innervation. Schwann cells (medium gray) are distributed between the innervation and at the base and apex of each MC. The additional immunochemical characteristics for each type of innervation are listed below the drawing.

medium or low on the basis of subjective relative comparisons among different sets of innervation within the same section. Otherwise, some antibodies consistently produced intense or faint labeling compared with others, but this is not necessarily indicative of the relative concentration of the different antigens. Because the label intensities often differed between the various antibodies, the images compiled for illustrative purposes in Figures 2-5 were adjusted using Northern Eclipse, Adobe (San Jose, CA) Photoshop, and Microsoft (Redmond, WA) Powerpoint software so that the maximum labeling intensity and contrast were comparable for each antibody.

\section{RESULTS}

\section{Three types of innervation to MCs}

As shown schematically in Figure 1, the MCs are typically supplied by several axons consisting of at least three immunochemically distinct types of innervation. Anti-PGP9.5 labeled all the innervation with a medium to high intensity (Fig. $2 A$ ). The innervation is distributed among tightly packed presumptive
Schwann cells and processes that expressed IR for the Schwann cell protein S100 as well as low-intensity PGP9.5-IR (Fig. 2A,B). Anti-S100 also labeled droplet-shaped presumptive Schwann cells loosely clustered at the base of the MCs (Fig. 2A,B).

Each type of $\mathrm{MC}$ innervation has a distinctive immunochemical characteristic as well as a predictable terminal distribution with respect to each other. Consistent with physiological evidence indicating that $\mathrm{A} \alpha \beta$-fibers supply low-threshold mechanoreceptive endings to $\mathrm{MCs}$, one type of $\mathrm{MC}$ innervation (Figs. $2 C$, $3 B-D$, 4, arrowheads) has a relatively large caliber and is the only type in the MCs that labeled with the antibodies against $200 \mathrm{kDa}$ NF. This innervation also is the only type that labeled with anti-myelin basic protein (MBP) (Fig. 2D). The other two types of MC innervation are thinner in caliber and lacked NF-IR or MBP-IR, indicating that they are unmyelinated C-fiber innervations. One type of unmyelinated innervation was clearly varicose and expressed relatively intense CGRP-IR (Fig. 3A-D, straight arrows). The terminations of most of these peptidergic $\mathrm{C}$-fibers are closely intertwined with the terminations of the NF-positive $\mathrm{A} \alpha \beta$-fibers, which also expressed CGRP-IR but at relatively lower levels (Fig. 3A-D). The other type of unmyelinated MC innervation did not label with anti-CGRP and was the only type that labeled with the anti-VR1 antibodies (Fig. 4A,B, curved arrows). This vanilloid $\mathrm{C}$-fiber innervation terminated in segregated zones interdigitated between zones containing the intertwined $\mathrm{A} \alpha \beta$ - and peptidergic C-fiber terminations (Fig. $4 A, B$ ). In several cases, the MC innervation consisted entirely of the VR1positive component (Fig. 4B).

To test for the possible presence of any other type of innervation that might not label with anti-NF, anti-CGRP, or anti-VR1, sections were incubated in a mixture containing all three of these antibodies, which were then all labeled with $\mathrm{Cy}$-3-conjugated secondary antibodies. Subsequent double labeling with antiPGP9.5 and a Cy-2-conjugated secondary antibody failed to reveal additional MC innervation.

\section{Analysis of multiple immunofluorescence characteristics}

The various panels in Figures 2-5 show many of the more informative double-labeling combinations and provide examples for each primary antibody that produced detectable labeling. Combinations are shown particularly involving anti-NF, anti-CGRP, or anti-VR1. Many other complementary double-label combinations are not shown. On the basis of the combined results of all double-labeled combinations and the relative locations within the MCs, the most likely profiles in Figures 2-5 are as follows: (1) the $\mathrm{NF}$-positive A $\alpha \beta$-fiber innervations is indicated by arrowheads; (2) the CGRP-positive C-fiber innervation is indicated by long straight arrows; and (3) the VR1-positive C-fiber innervation is indicated by curved arrows. Broad arrows in some figures indicate other innervation to the epidermis, which also provided comparisons for assessing the relative specificity of the primary antibodies and double-label combinations.

\section{$A \alpha \boldsymbol{\beta}$ innervation}

As was noted above, the $\mathrm{A} \alpha \beta$ innervation (arrowheads) was labeled with the mouse monoclonal antibody RT97 made against phosphorylated $200 \mathrm{kDa} \mathrm{NF}$ and rabbit polyclonal antibody made against nonphosphorylated $200 \mathrm{kDa}$ NF (Fig. 2C). Several A $\alpha \beta$ axons could innervate a single MC. Among all the antibodies used in this study, the immunoreactivity for both NF antibodies was consistently the most intense and was the most uniform 

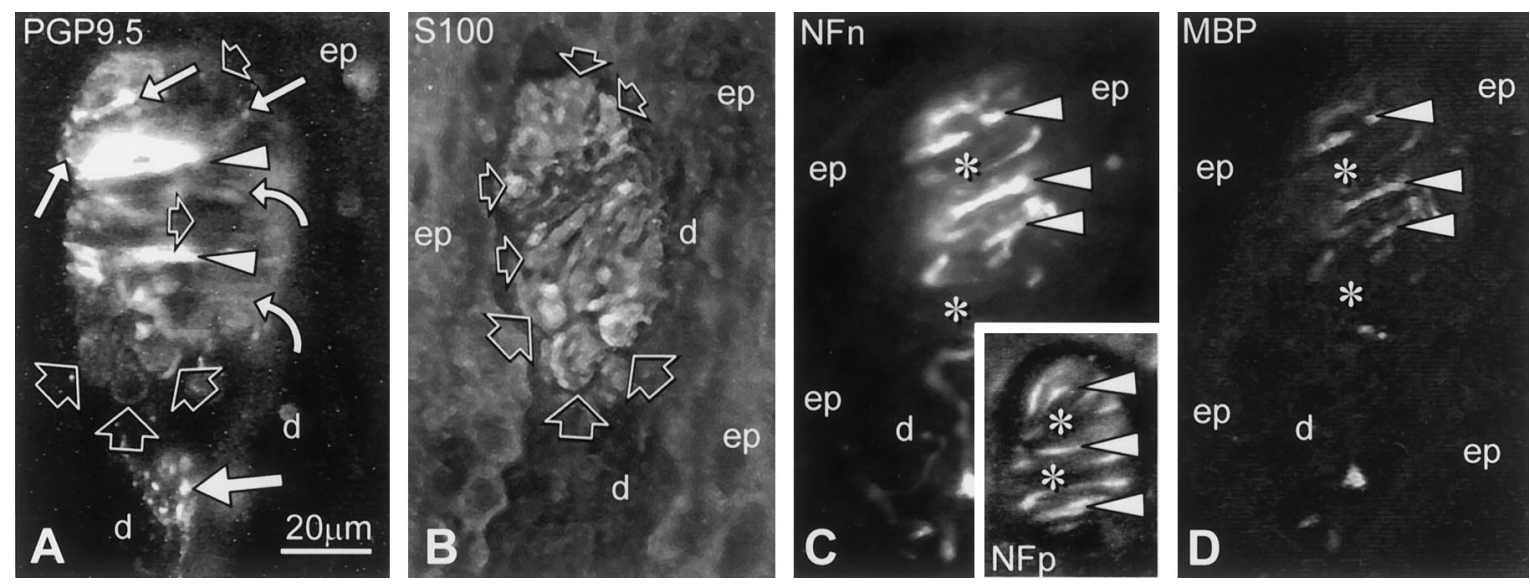

Figure 2. Immunofluorescence labeling of MCs in 14- $\mu$ m-thick sections cut perpendicular to the surface of the glabrous skin of a distal digit pad. The antigens for the primary antibodies are indicated. ep, Epidermis; $d$, dermis. $A$, MCs have a stratified appearance, as seen with rabbit anti-PGP9.5. The most intense PGP9.5-IR (arrowheads) occurs on processes of relatively thick-caliber A $\alpha \beta$-fiber innervation that were labeled with anti-NF in other double-labeled preparations (Figs. 3A-D, 4). Intense PGP9.5-IR also occurs on thinner beaded profiles (straight arrows) that were labeled with anti-CGRP and anti-SP in other double-labeled preparations (Fig. 3). The large straight arrow indicates likely source axons; the small straight arrows indicate presumptive terminals. Relatively medium-intensity PGP9.5-IR (curved arrows) occurs on the innervation that labels with anti-V R1 in other preparations (Fig. 4) and is restricted to zones between the A $\alpha \beta$-fiber and CGRP-positive C-fiber innervation. $B$, Rabbit anti-S100 labels flattened presumptive Schwann cells (small broad arrows) between the axon terminals and teardrop-shaped, presumptive Schwann cells (large broad arrows) at the base and apex of the MCs. The Schwann cells also express low levels of PGP9.5-IR (A, broad open arrows). $C$, $D$, Double labeling with rabbit anti-nonphosphorylated $200 \mathrm{kDa}$ neurofilament protein (NFn) and mouse anti-MBP reveals that myelin basic protein is expressed along the A $\alpha \beta$-derived processes (arrowheads) within the MC. Labeling with mouse anti-phosphorylated $200 \mathrm{kDa}$ neurofilament protein $(N F p)$ is similar to labeling with rabbit anti-NFn $(C$, inset, arrowheads). Asterisks indicate NF-negative zones where VR1-positive C-fiber innervation terminates as revealed by double-label combinations (Fig. 4).

throughout both the axons and terminals. MBP-IR was coexpressed among many of the NF-positive processes within the MC (Fig. 2C,D), suggesting that myelin continues onto terminal branches of the $\mathrm{A} \alpha \beta$ axons within close proximity to the endings. Relatively thinner NF-positive (Fig. 4A, broad arrows) and MBPpositive innervation supplied the epidermis and is presumably A $\delta$-fiber innervation. No such thin-caliber NF-positive innervation supplied the MCs.

As seen by conventional epifluorescence microscopy, the NFpositive MC innervation consistently expressed completely coextensive CGRP-IR (Fig. 3A-C). In comparison with the relatively high intensity of CGRP-IR on some thin varicose NF-negative axons entering the MCs (Fig. $3 A$, large red arrow), the coexpression of CGRP-IR was in general lower on the NF-positive terminals and was faint on the NF-positive source axons (Fig. 3A-C, small and large arrowheads). CGRP-IR was often fairly intense, typically along the inferior margin of many NF-positive terminals (Fig. $3 A-C$, small red arrows). Confocal microscopy revealed that this higher-intensity CGRP-IR was in C-fiber terminals closely affiliated with many endings of the A $\alpha \beta$-fibers (Fig. $3 D$ ). Immunofluorescence for anti-SP (Fig. 3E-G, arrowheads and long arrows) was consistently coextensive with anti-CGRP labeling but was much less intense on the same types of innervation and had much higher background especially in the epidermis. As seen with anti-CGRP, anti-SP labeling was also present on the endings of the $\mathrm{A} \alpha \beta$-fibers but was relatively more intense where the CGRP-positive $\mathrm{C}$-fibers were seen to terminate along the inferior borders of $\mathrm{A} \alpha \beta$ endings. Interestingly, the $\mathrm{A} \alpha \beta$ endings expressed IR for the SP receptor NK1 (Figs. $3 E-G$ ), suggesting that the CGRP-positive $\mathrm{C}$-fibers may have a functional impact on the $\mathrm{A} \alpha \beta$ endings. Low levels of SP within the $\mathrm{A} \alpha \beta$ endings might be attributable to uptake from the closely affiliated $\mathrm{C}$-fiber terminals.

The definitive combination of immunofluorescence characteristics of the $\mathrm{A} \alpha \beta$ innervation to the MCs is summarized in Figure 1. As indicated in Figure 5, arrowheads, the $\mathrm{A} \alpha \beta$ innervation of the MCs also coexpressed IR for the $\alpha 2 \mathrm{~A}$ and $\alpha 2 \mathrm{C}$ adrenergic receptors (Fig. 5I,J), the $\delta$ opioid receptor $(\delta \mathrm{OR})($ Fig. $5 D)$, and the vanilloid-receptor-like receptor 1 (VRL1) (Fig. 5L). The A $\alpha \beta$ innervation also had detectable IR for the ATP-gated ion channels P2X2 and P2X3 (Fig. 5B,H). Although the coexpression of some antibody labeling with NF-IR is not shown directly in many of the figures, the position of the NF-positive endings could be discerned based on the following: (1) their relatively larger caliber; (2) their known coexpression of medium levels of CGRP-IR and their close relationship with more intense CGRP-positive C-fiber terminals (Figs. $3 A-D, 5 H-J$ ); and (3) their segregation from the VR1-positive innervation (Figs. 4, 5B,D). Coexpression of various immunoreactivities that are not specifically shown in Figures 2-5 was directly confirmed through double labeling with either the monoclonal or polyclonal NF antibodies. The $\mathrm{A} \alpha \beta$ innervation consistently failed to label with antibodies against $\mu \mathrm{OR}, \kappa \mathrm{OR}, \mathrm{P} 2 \mathrm{X} 1$, and VR1 or nociceptin-orphanin FQ (NOCI), which is an endogenous ligand for the orphan opioid receptor (Figs. 4, 5C,E, $K$ ). With the exception of P2X2 (Fig. 5B), colabeling for the various receptors and channels was generally more intense on NF-positive profiles within the MCs than on their source axons. The labeling for the $\mathrm{P} 2 \mathrm{X} 2$ receptors was consistently more intense and extensive than that of $\mathrm{P} 2 \mathrm{X} 3$ (Fig. 5B, $H$ ).

Another large-caliber NF- and MBP-positive innervation terminates on Merkel cells in the lamina basalis at the base of epidermal folds (Fig. 4A, bent arrows). The Merkel cells lack pigment seen in adjacent melanocytes (Fig. 4A, asterisks) but expressed CGRP-IR (results not shown) as seen in other species (Rice et al., 1997; Rice and Rasmusson, 2000). In contrast to the $\mathrm{A} \alpha \beta$ innervation to the MCs, the Merkel innervation was only labeled definitively with anti-PGP9.5, -NF, -S100, and -MBP.

\section{Unmyelinated peptidergic innervation}

As was noted above, a relatively thin-caliber varicose innervation to MCs lacked NF- and MBP-IR but expressed relatively high 

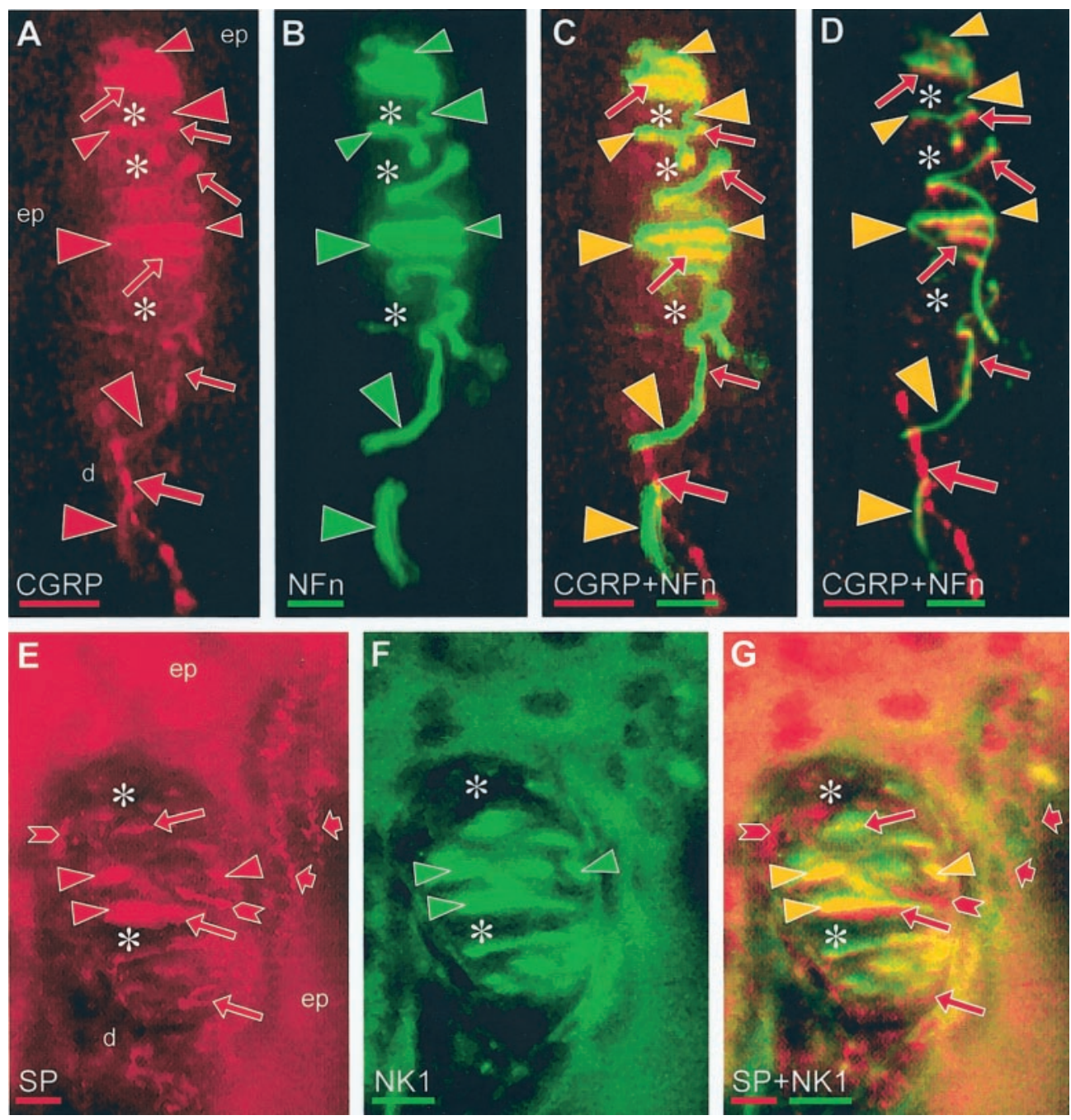

Figure 3. The close relationship is shown between the peptidergic C-fiber (arrows) and A $\alpha \beta$-fiber (arrowheads) MC innervation as seen in immunofluorescence digital images of $14-\mu \mathrm{m}$-thick double-labeled sections cut perpendicular to the skin surface. ep, Epidermis; $d$, dermis. $A-D$, The same MC is shown labeled with sheep anti-CGRP and rabbit anti-NFn. In $E-F$, another MC is labeled with guinea pig anti-SP and rabbit anti-NK1. The antigens labeled by the primary antibodies are indicated at the bottom. The color bar beneath each antigen indicates that the primary antibody was revealed by secondary antibodies conjugated to $\mathrm{Cy}-3$ (red) or Cy-2 (green). In images captured with just the $\mathrm{Cy}-3$ filter $(A, E)$, the labeled innervation is red and is indicated by red symbols. In images captured with just the Cy-2 filter $(B, F)$, the labeled innervation is green and is indicated by green symbols. In digitally merged double-labeled images $(C, D, G)$, yellow symbols indicate the innervation definitively labeled with both primary antibodies. Asterisks indicate zones where VR1-positive C-fiber innervation is interdigitated, as seen in other double-label preparations (Fig. 4). $A-C$, Deconvoluted digital images of conventional epifluorescence for anti-CGRP and anti-NFn. In the tissue section, the maximum intensity of anti-CGRP labeling was lower, and the background was higher than anti-NFn labeling. For illustration purposes, the intensity of the anti-CGRP image has been digitally increased approximately twofold so that the maximum intensity was comparable with the maximum intensity of the anti-NFn image. The higher background of the CGRP labeling was partially suppressed by increasing the contrast and digitally subtracting lower signals. Resulting images in $A$ and $B$ are digitally merged in $C$. The NFn labeling is in relatively thicker profiles that colabel with anti-MBP in other sections (Fig. $2 C, D$ ), indicating that the detectable $\mathrm{NF}$ expression is in $\mathrm{A} \alpha \beta$ innervation. The intensity of $\mathrm{NFn}$ labeling is very high and uniform in the $\mathrm{A} \alpha \beta$ axons (large arrowheads) as well as in their presumptive endings (small arrowheads). In contrast, the intensity of anti-CGRP labeling varies and is highest only in relatively thin, varicose axons (large arrow) that fail to colabel with anti-MBP in other double-labeled preparations, indicating that they are C-fibers. Other thin, varicose axons are faintly labeled with anti-CGRP (chevrons). CGRP-IR is coexpressed at relatively low levels on the anti-NFn-labeled axons (large arrowheads) and at fairly high levels on anti-NFn-labeled presumptive endings (small arrowheads), especially along the lower border of the endings. $D$, Confocal image showing double labeling of the same MC as in $A-C$. Separate confocal images of the CGRP-IR and NF-IR were captured; the intensity of the anti-CGRP labeling was increased so that the maximum was comparable with the maximum for anti-NFn; and the two images were merged. Low- to medium-range signals were subtracted for both anti-CGRP and anti-NFn so that only sites with the most intense labeling remain. With the elimination of medium-intensity CGRP-IR from the NF-positive endings, the confocal images revealed that innervation having high levels of CGRP (small red arrows) is intertwined with the NF-positive innervation and is especially located along the inferior border of the NF-positive endings. $E-G$, Deconvoluted conventional epifluorescence images of an MC double-labeled for SP and N K1. Original immunofluorescence signals with anti-SP and anti-N K1 were much lower than those with anti-CGRP and anti-NF. For illustration purposes, the intensity of the images in $E$ and $F$ have been digitally increased threefold to fourfold so that the maximum signals are comparable with each other and with the maximum signals in $A$ and $B$. Consequently, background labeling is also increased especially for anti-SP, which has relatively low signal to high background labeling particularly in the epidermis. Some amplified background labeling was reduced by increasing the contrast and digitally subtracting lower signals. Comparable with the pattern of labeling observed with anti-CGRP and anti-NF $(A, B)$, SP- and NK1-IR are coexpressed on the presumptive endings (arrowheads) of A $\alpha \beta$ axons confirmed by double-label combinations with anti-NF (results not shown). The A $\alpha \beta$ axons lack detectable SP-IR and have relatively low levels of NK1-IR. Merged images in $G$ reveal separate SP-positive innervation (long arrows) along the inferior border of the $\mathrm{A} \alpha \beta$ endings. A few profiles that only label with anti-SP are independently present in the MC (chevrons) and in the epidermis (broad arrows). 


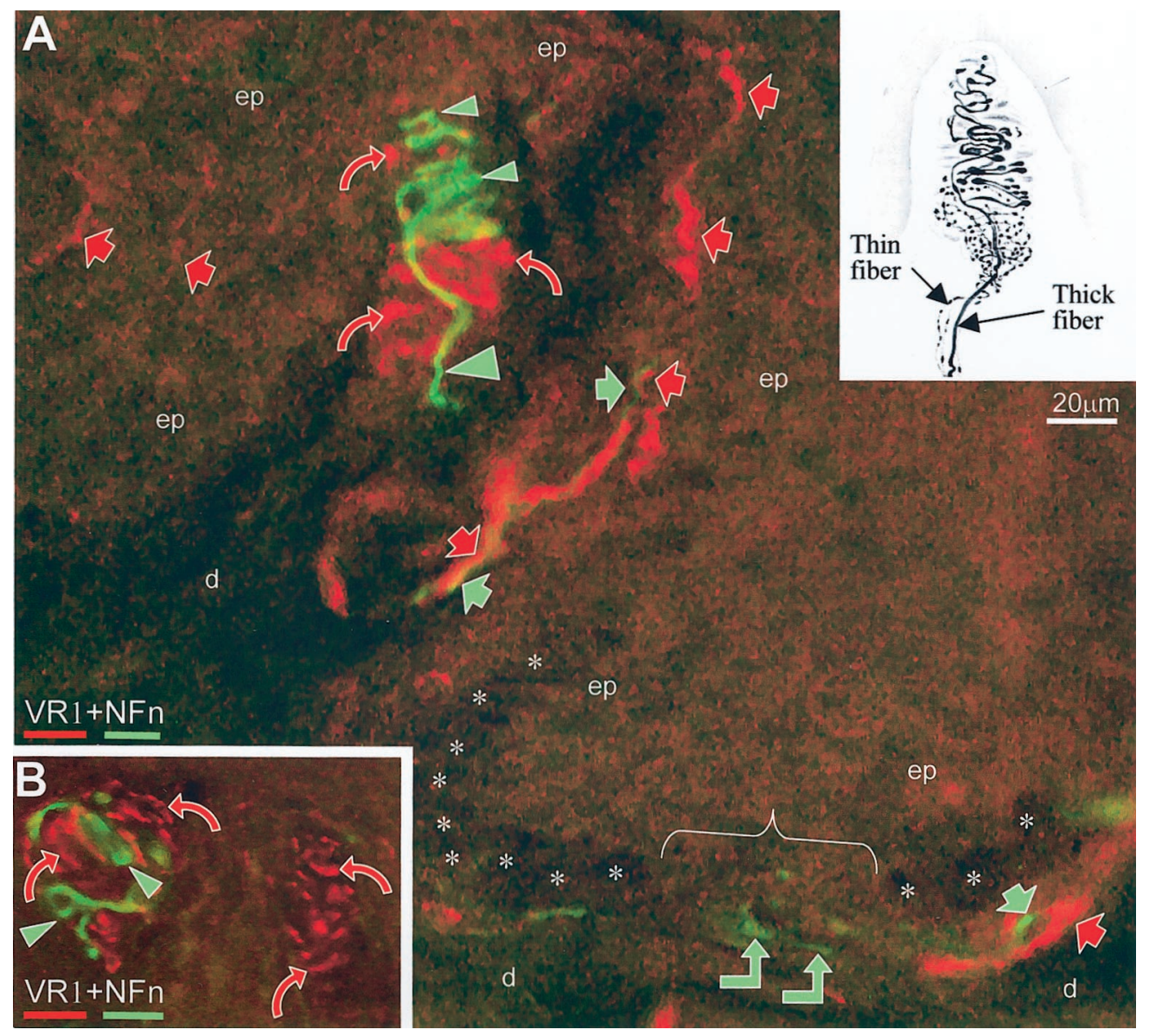

Figure 4. Segregated, interdigitated relationship between the VR1-positive C-fiber innervation (curved arrows) and NF-positive A $\alpha \beta$-fiber innervation (arrowheads) as seen in double-labeled conventional immunofluorescence digital images of 14- $\mu \mathrm{m}$-thick sections cut perpendicular to the skin surface. $e p$, Epidermis; $d$, dermis. The sections were double-labeled with guinea pig anti-VR1 revealed with a Cy-3-conjugated secondary antibody (red labeling indicated by red arrows) and rabbit anti-NFn revealed with a Cy-2-conjugated secondary antibody (green labeling indicated by green arrows and arrowheads). In original images captured separately for Cy-3 and Cy-2, anti-VR1 labeling was lower, and background was higher than anti-N Fn labeling. For illustration purposes, the intensity of the anti-VR1 image was digitally increased approximately threefold so that the maximum intensity was comparable with the maximum intensity of the anti-NFn image. The higher background of the VR1 labeling was partially suppressed by increasing the contrast and digitally subtracting lower signals. The resulting separate images are digitally merged in $A$ and $B$. No innervation was definitively double-labeled in the MCs or epidermis. VR1-positive innervation in the MCs is segregated from and interdigitated with NF-positive innervation. Other double-label combinations revealed that the anti-NFn labeling is on myelinated $\mathrm{A} \alpha \beta$-fiber innervation (Fig. $2 C, D)$ and that the VR1 innervation is on unmyelinated C-fiber innervation that lacks CGRP-IR (Fig. 5A). A, inset, Drawing by Dogiel (1892) illustrating a similar segregation of thin and thick fiber innervation in human MCs based on a reduced silver stain. In $A$, anti-VR1 and anti-NFn label separate thin-caliber innervation terminating in the epidermis (red and green broad arrows). Asterisks indicate individual melanocytes in the lamina basalis of the epidermis. The white bracket indicates a gap in the row of melanocytes. The gap is occupied by melanin-lacking Merkel cells, which are labeled by anti-CGRP in other preparations (results not shown). The Merkel cells are innervated by anti-NFn labeled endings (green bent arrows) supplied by A $\alpha \beta$-fibers. In $B$, the right MC only has the VR1-positive innervation.

levels of CGRP-IR and coexpressed SP-IR (Fig. 3, long straight arrows). The presence of this CGRP-positive C-fiber innervation was verified by using anti-CGRP raised in rabbits and sheep (Table 1). The coexpression of SP was determined by double labeling with an SP antibody raised in guinea pig (Table 1). In most cases, double labeling for other antigens was done in combination with the rabbit or sheep CGRP antibodies (Fig. $5 A, G-J$ ), because the guinea pig anti-SP had relatively high background labeling (Fig. 3E).

As was resolved by confocal microscopy, the peptidergic $\mathrm{C}$-fiber innervation to the MCs is typically closely affiliated with the inferior border of the NF-positive $\mathrm{A} \alpha \beta$ endings (Fig. 3D). Some peptidergic fibers were located around the perimeter of the MCs (Fig. 5A,B). Other thin-caliber innervation terminating in the epidermis also can express CGRP- and SP-IR (Figs. $3 E, G$, $5 H-J$, broad arrows). NF- and MBP-IR were coexpressed on some of the peptidergic epidermal innervation but were lacking on others (results not shown). Some peptidergic epidermal innervation also coexpressed VR1-IR. Thus, the peptidergic innervation to the epidermis appears to be a mix of $\mathrm{C}$ - and $\mathrm{A} \delta$-fiber innervation, some of which expresses VR1-IR. In contrast, the peptidergic C-fiber innervation to the MCs was only NF- and VR1negative (Figs. $3 A-D, 5 A$, long straight arrows).

The definitive combination of immunofluorescence characteristics of the CGRP-positive C-fiber innervation to the MCs is summarized in Figure 1. Characteristics in addition to SP-IR are shown in Figure 5 (long straight arrows). In those panels that do not directly show anti-CGRP labeling, the location of the CGRPpositive $\mathrm{C}$-fiber innervation could be discerned on the basis of (1) its close relationship with the larger-caliber NF-positive $\mathrm{A} \alpha \beta$ endings (Fig. $3 A-D$ ) and (2) its segregated distribution from the VR1-positive innervation (Fig. 5A). In contrast to the $\mathrm{A} \alpha \beta$ in- 

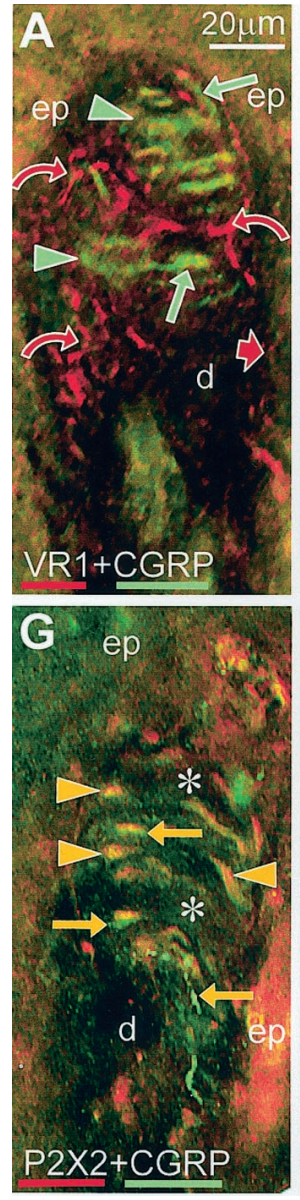
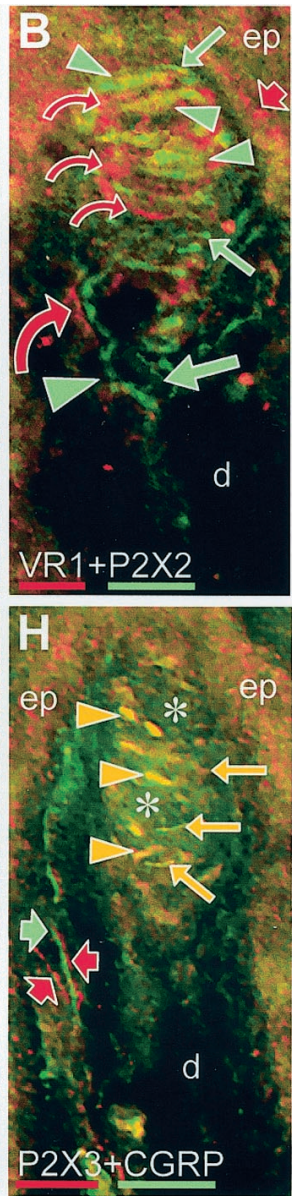
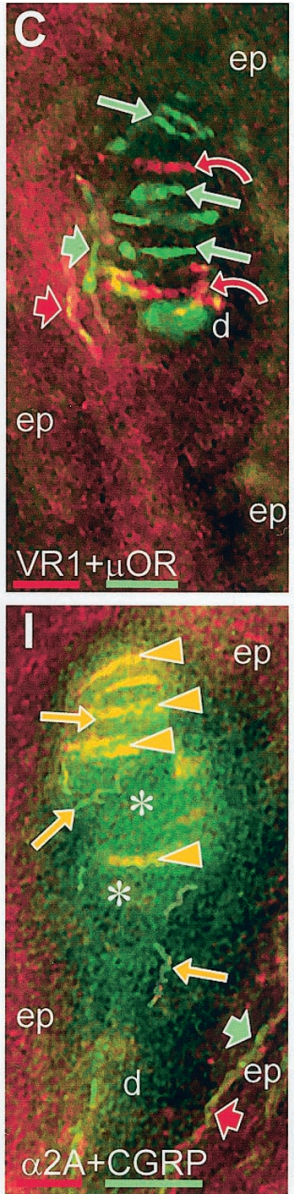
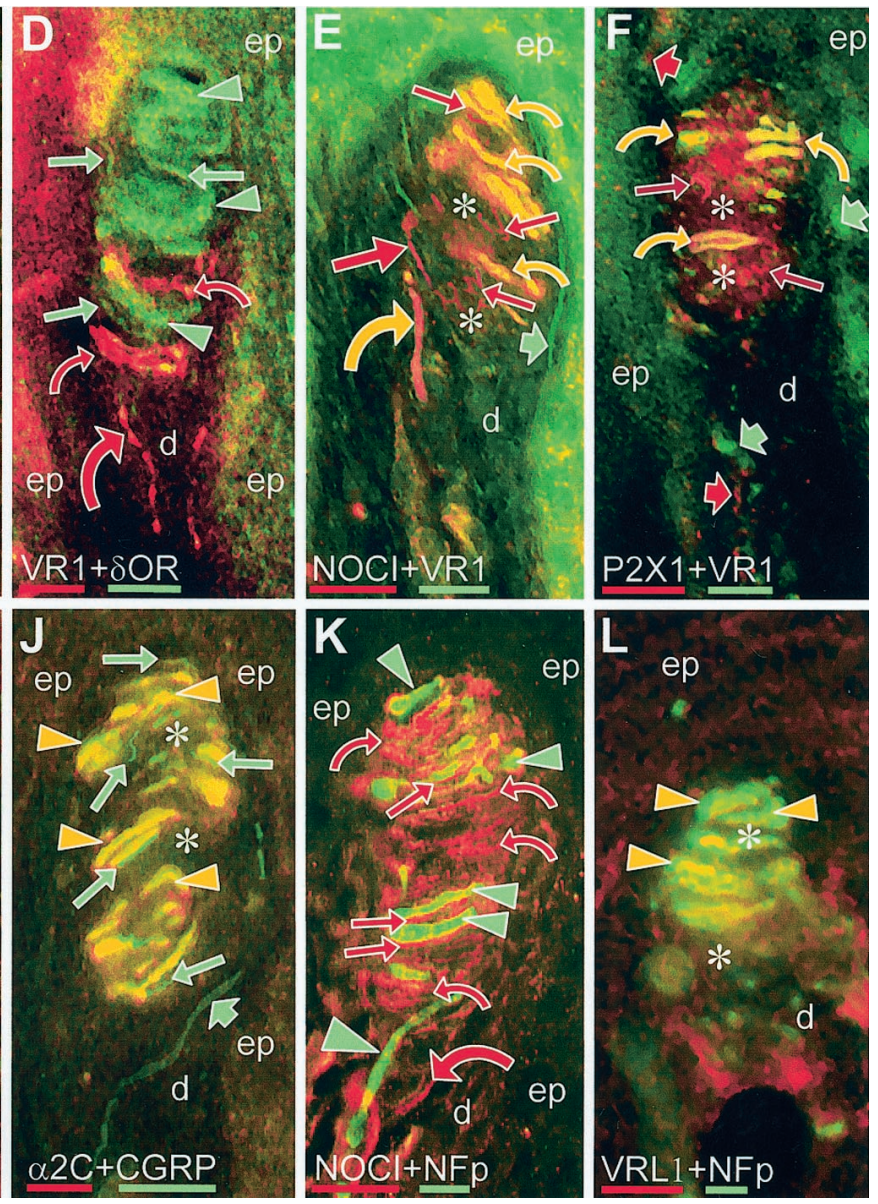

Figure 5. Additional immunochemical characteristics of MC innervation as seen in conventional immunofluorescence digital images of MCs in $14-\mu \mathrm{m}$-thick sections cut perpendicular to the skin surface. ep, Epidermis; $d$, dermis. Each panel is an image double-labeled with two primary antibodies made in different species against the antigens indicated at the bottom. The fluorophore conjugated to the secondary antibodies is indicated by a red bar (Cy-3) or green bar (Cy-2) located beneath the antigen of the correspondingly labeled primary antibody. Based on morphology, location, and the total results of all double-label combinations used in the study (Figs. 3, 4), the likely NF-positive A $\alpha \beta$-fiber innervation is indicated by arrowheads; likely CGRP-positive C-fiber innervation is indicated by long straight arrows; and likely VR1-positive C-fiber innervation is indicated by curved arrows Epidermal innervation is indicated by broad arrows in some panels. Red and green arrowheads and arrows indicate processes definitively labeled only by the antibody for the antigen listed over the red and green bars, respectively. Yellow arrowheads and arrows indicate definitively double-labeled innervation. Large arrows and arrowheads indicate likely source axons; small arrows and arrowheads indicate presumptive terminals. For illustration purposes, the image intensities were digitally adjusted so that the maximum labeling intensity for each primary-secondary antibody combination was approximately the same. In many cases, contrast was increased, and low-end signals were subtracted to partially reduce the relatively high background labeling that occurs with some antibodies, the increased background caused artificially by digitally enhancing the overall image intensity, or both. $A$, Guinea pig anti-VR1 labeled C-fiber innervation (red curved arrows) is segregated from innervation labeled with rabbit anti-CGRP-IR. On the basis of other preparations (Fig. $3 A-D$ ), the segregated CGRP-positive innervation includes intermingled CGRP-positive endings of A $\alpha \beta$-fibers (green arrowheads) and C-fibers (green long straight arrows). Some epidermal innervation expresses only VR1-IR (broad red arrow) or CGRP-IR (results not shown). $B$, Rabbit anti-P2X2 labeling (green arrows and arrowheads) is segregated from innervation labeled with guinea pig anti-VR1 (red curved arrows). As determined from other preparations (e.g., G), P2X2-IR is expressed on both the CGRP-positive C-fiber innervation (green arrows) and A $\alpha \beta$-fiber innervation ( green arrowheads). C, guinea pig anti-VR1 (red curved arrows) and rabbit anti- $\mu \mathrm{OR}$ ( green straight arrows) label separate sets of innervation in the MC. On the basis of other label combinations (results not shown), the $\mu$ OR-IR was definitive only on the CGRP-positive C-fiber innervation. A few spots of $\mu$ OR-IR coincide with the VR1-positive innervation, but this was not consistent. Anti- $\mu$ OR and anti-VR1 label mostly separate epidermal innervation (red and green broad arrows). D, Rabbit anti- $\delta \mathrm{OR}$ labels innervation (green arrows and arrowheads) in zones between the guinea pig anti-VR1-positive innervation (red curved arrows). Other label combinations (results not shown) revealed that the $\delta \mathrm{OR}-\mathrm{IR}$ is expressed on the A $\alpha \beta$-fiber innervation and on the CGRP-positive C-fiber innervation. A few spots of $\delta \mathrm{OR}$-IR coincide with the VR1-positive innervation, but this was not consistent. E, Rabbit anti-NOCI labeling is coexpessed (yellow curved arrows) on guinea pig anti-VR1-positive innervation in the MCs. As determined from other preparations (e.g., $K$ ), other anti-NOCI labeling (red straight arrows) is likely on the CGRP-positive C-fiber innervation. Asterisks indicate VR1-negative zones where the A $\alpha \beta$-fiber and CGRP-positive C-fibers terminate (Figs. 3, 4). Some epidermal innervation is VR1-positive and NOCI-negative (green broad arrow). F, Rabbit anti-P2X1 labeling is highly punctate. Some is detectable on guinea pig VR1-positive innervation ( yellow curved arrows) in the MCs. As determined in other double-label combinations (results not shown), P2X1-IR is also expressed on CGRP-positive C-fiber innervation (red straight arrows). Asterisks indicate VR1-negative zones where the A $\alpha \beta$-fiber and CGRP-positive C-fibers terminate. VR1-IR and P2X1-IR can be expressed on separate epidermal innervation (red and green broad arrows). G, H, Rabbit anti-P2X2 and anti-P2X3 colabels with sheep CGRP-IR both on the CGRP-positive C-fiber innervation (yellow straight arrows) and on the A $\alpha \beta$-fiber innervation (yellow arrowheads), as determined from other preparations. Both P2X2-IR and P2X3-IR are relatively fainter on the C-fiber innervation. Asterisks indicate CGRP-, P2X2-, and P2X3-negative zones where the VR1-positive innervation terminates (Fig. 4). Anti-P2X3 labeling is more readily detectable than anti-P2X2 on epidermal innervation, where it can be independent of CGRP expression (red and green broad arrows). I, Rabbit $\alpha 2 \mathrm{~A}-\mathrm{IR}$ is coexpressed on sheep anti-CGRP-labeled $\mathrm{C}$-fiber (yellow long arrows) as well as coexpressed more intensely on the A $\alpha \beta$-fiber innervation (yellow arrowheads), as determined from other double-label combinations (results not shown). The $\alpha$ 2A-IR and CGRP-IR can be expressed on separate axons terminating in the (Figure legend continues). 
nervation, the CGRP-positive C-fiber innervation to the MCs coexpressed $\mu$ OR-IR in addition to $\delta$ OR-IR (Fig. $5 C, D$ ). In other preparations, which are not shown, all of the MC innervation that labeled with rabbit anti- $\mu$ OR also labeled with sheep anti-CGRP, whereas rabbit anti- $\mu \mathrm{OR}$ failed to label innervation that binds mouse anti-NFn. Thus, anti- $\mu \mathrm{OR}$ only definitively labeled the CGRP-positive C-fiber innervation. The CGRP-positive C-fiber innervation also coexpressed immunoreactivity for the $\mathrm{P} 2 \mathrm{X} 1 \mathrm{pu}-$ rinergic receptor as well as $\mathrm{P} 2 \mathrm{X} 2$ and $\mathrm{P} 2 \mathrm{X} 3$ (Fig. $5 B, G, H$ ) for the $\alpha 2 \mathrm{~A}$ adrenergic receptor but not $\alpha 2 \mathrm{C}$ (Fig. 5I,J) and for NOCI (Fig. $5 E, K$ ). Coexpression of various immunoreactivities that are not specifically shown in Figures 3-5 was directly confirmed through double labeling with either the rabbit or sheep antibodies for CGRP. The peptidergic C-fiber innervation lacked labeling for VRL1, $\kappa \mathrm{OR}$, and VR1 (Fig. 5A).

\section{Unmyelinated vanilloid receptor innervation}

The presence of VR1-positive innervation (Figs. 4, 5, curved arrows) was confirmed with three different antibodies against VR1 (Table 1) made in two different laboratories, in two different species (rabbit and guinea pig), and against either the $\mathrm{C}$ - or $\mathrm{N}$-terminal ends of the receptor. The VR1 antibody made in guinea pig was most widely used in double-label combinations, because it gave more intense labeling at higher dilutions and because most of the other antibodies used in this study were raised in rabbit. The definitive combination of immunofluorescence characteristics of the VR1-positive C-fiber innervation to the MCs is summarized in Figure 1. Other than PGP9.5-IR and VR1-IR, the unmyelinated vanilloid innervation only colabeled with anti-NOCI and -P2X1 (Fig. 5E,F,K). Anti-VR1 also labeled many thin-caliber endings in the epidermis, which never coexpressed NF-IR (Fig. 4A). However, unlike in the MCs, some of the VR1-positive endings in the epidermis coexpressed IR for CGRP, and many were labeled with the antibodies for $\alpha 2 \mathrm{~A}, \mathrm{P} 2 \mathrm{x} 2$, and $\mathrm{P} 2 \mathrm{X} 3$ (results not shown). The full range of immunochemical characteristics for the epidermal vanilloid innervation is being explored further but serves to illustrate that labeling combinations could be found among the epidermal innervation that differed from those among the various types of MC innervation. This supports the specificity of the various types of antibodies for particular types of innervation and rules out the likelihood of false-positive results or nonspecific cross-binding among the various primary and secondary antibodies.

\section{DISCUSSION}

Our study shows that MCs in the digital glabrous skin of monkeys are multiafferented end organs with three distinct types of innervation: an $\mathrm{A} \alpha \beta$-fiber type and two $\mathrm{C}$-fiber types. The $\mathrm{A} \alpha \beta$-fibers are the likely source of rapidly adapting, low-threshold mechanoreceptive endings that detect low-frequency vibration and microgeometric surface features (Talbot et al., 1968; Srinivasan et al., 1990; Blake et al., 1997a,b). In addition to confirming a CGRPpositive $\mathrm{C}$-fiber innervation observed recently in humans by Jo- hansson et al. (1999), our results show that this innervation is closely affiliated with the $\mathrm{A} \alpha \beta$-fiber endings which also express low levels of CGRP-IR and SP-IR. The most surprising new finding was a nonpeptidergic VR1-positive C-fiber innervation that terminated in segregated zones interdigitated between the $\mathrm{A} \alpha \beta$-fiber and peptidergic $\mathrm{C}$-fiber terminations. Interestingly, the only other report of such a segregated arrangement of "thin-fiber" and "thick-fiber" innervation in MCs was by Dogiel (1892).

Importantly, both CGRP and SP have been implicated in mediating nociception (Oku et al., 1987; Duggan et al., 1990; Urban et al., 1995). Also, the VR1 receptor has been identified as the likely mediator of intense evoked pain after topical application of capsaicin, a VR1 agonist (Tominaga et al., 1998; Caterina et al., 2000). VR1 also expresses physiological properties consistent with acidic $\mathrm{pH}$ and high-temperature nociception (Caterina et al., 1997; Tominaga et al., 1998). Thus, the MCs may have nociceptive capabilities in addition to low-threshold mechanoreception. Consistent with this possibility, all three types of innervation also express additional immunochemical characteristics implicated in nociception.

\section{Relationship between $\mathbf{A} \alpha \boldsymbol{\beta}$-fiber and peptidergic C-fiber innervation}

Consistent with intense CGRP-IR and SP-IR on smaller dorsal root ganglion (DRG) neurons (Lindh et al., 1989; McCarthy and Lawson, 1990), CGRP- and SP-IR were clearly expressed on both the axons and endings of the peptidergic C-fiber innervation. Surprisingly, CGRP- and SP-IR were also expressed at relatively low levels on the closely affiliated $\mathrm{A} \alpha \beta$-fiber endings but were barely detectable in the source axons. Likewise, low levels of CGRP and SP immunolabeling were previously observed in lanceolate ending palisades affiliated with rat guard hairs but were lacking in their $\mathrm{A} \beta$ source axons (Rice et al., 1997). These lanceolate endings also have a close affiliation with a CGRP- and SP-positive C-fiber innervation and are also thought to be rapidly adapting mechanoreceptors. The presence of low levels of CGRP and SP labeling on these A-fiber endings may be endogenous, because many medium to large DRG neurons express CGRP and SP at low levels (Lindh et al., 1989; McCarthy and Lawson, 1990). Also, many large-caliber myelinated axons have been shown to contain increased levels of SP-IR after inflammation (Neumann et al., 1996). This increase has been implicated in the contribution of large-caliber A-fibers to allodynia caused by inflammatory conditions. Alternatively, the presence of NK1 suggests that MC $\mathrm{A} \alpha \beta$-fiber endings may be binding peptides released by the peptidergic C-fiber innervation (Maggi, 1995). Consequently, the peptidergic $\mathrm{C}$-fibers may play an effector role in the function or maintenance of the $\mathrm{A} \alpha \beta$-fiber innervation (Kruger, 1988; Kruger et al., 1989). Consistent with a maintenance role, some MCs only had NK1-negative, VR1-positive C-fiber innervation.

\section{$\longleftarrow$}

(Figure legend continues.) epidermis (red and green broad arrows). J, Rabbit anti- $\alpha$ 2C labeling is coexpressed only on the CGRP-positive profiles that are the thicker endings of the $\mathrm{A} \alpha \beta$ innervation (yellow arrowheads). CGRP-positive C-fiber innervation is present without $\alpha 2 \mathrm{C}$-IR in and around the MCs (green long arrows) and supplying the epidermis (green broad arrow). Asterisks indicate the CGRP and $\alpha 2 \mathrm{C}$-negative zones where the VR1-positive innervation would be located. $K, \mathrm{~A} \alpha \beta$ innervation labeled with mouse anti-NFp (green arrowheads) has little if any definitive rabbit anti-NOCI-IR. Anti-NOCI labels innervation (red curved arrows) between the A $\alpha \beta$ endings, which is where the VR1 innervation terminates (see E), as well as innervation (red straight arrows) closely juxtaposed to the A $\alpha \beta$ endings, which is where the CGRP-positive C fibers terminate. $L$, Rabbit anti-VRL1-IR is only definitively colocalized with mouse anti-NFp labeling, indicative of the $\mathrm{A} \alpha \beta$-fiber innervation. 


\section{Other nociceptive immunofluorescence properties of $\mathbf{A} \boldsymbol{\alpha} \boldsymbol{\beta}$ - and peptidergic $\mathbf{C}$-fibers}

Purinergic receptors

Both the $\mathrm{A} \alpha \beta$-fiber and peptidergic $\mathrm{C}$-fiber innervations also express IR for $\mathrm{P} 2 \mathrm{X} 2$ and $\mathrm{P} 2 \mathrm{X} 3$ receptors. Heteropolymerization of both subunits has been shown to provide a channel having ATP-evoked transient and persistent currents associated with nociceptors (Lewis et al., 1995; Cook et al., 1997). Also, several studies showed that perfusion of ATP or P2X agonists can elicit pain (Bleehen and Keele, 1977; Bland-Ward and Humphrey, 1997; Hamilton et al., 2000) and can induce mechanical allodynia in normal control and neonatal capsaicin-treated rats (Tsuda et al., 2000). However, a P2X3 knock-out study indicates that P2X3 receptors may be involved more in inflammatory pain processing than acute pain response (Souslova et al., 2000).

\section{Opioid receptors}

Both the $\mathrm{A} \alpha \beta$ innervation and peptidergic $\mathrm{C}$-fiber innervation expressed IR for opioid receptors. Local administration of low doses of opioids has been shown to elicit potent analgesic effects in inflamed tissue by activating primarily opioid receptors on primary afferent neurons (Stein, 1995; Zhou et al., 1998). Both the CGRP-positive $\mathrm{C}$-fibers and $\mathrm{A} \alpha \beta$-fibers in the MCs express the $\delta \mathrm{OR}$ receptor, which has previously been observed in the membrane of CGRP-containing synaptic vesicles (Q. Zhang et al., 1998; X. Zhang et al., 1998). This supports the possibility that the $\mathrm{A} \alpha \beta$-fiber innervation is truly peptidergic in nature.

Only the peptidergic $\mathrm{C}$-fiber innervation had detectable levels of $\mu \mathrm{OR}$, which is normally expressed in terminal membranes and may directly suppress release of neuropeptides (Ballet et al., 1998). Restricted expression of $\mu \mathrm{OR}-\mathrm{IR}$ on the NF-negative $\mathrm{C}$-fiber innervation agrees with observations that $\mu \mathrm{OR}$ staining in rat DRGs was predominantly on small to medium-size neurons lacking NF-IR (Arvidsson et al., 1995b). Our observation that $\mu \mathrm{OR}-\mathrm{IR}$ is colocalized with $\delta \mathrm{OR}$-IR on peptidergic C-fiber MC innervation is consistent with their coexpression on small neurons in rat DRGs (Arvidsson et al., 1995b) and on unmyelinated axons in rat glabrous skin (Coggeshall et al., 1997). The absence of $\mu \mathrm{OR}-\mathrm{IR}$ on the $\mathrm{A} \alpha \beta$-fiber MC innervation agrees with observations that significantly more axons are $\delta \mathrm{OR}$-positive than $\mu \mathrm{OR}$ positive (Coggeshall et al., 1997). Consistent with rare $\kappa \mathrm{OR}$ labeling in DRGs (Q. Zhang et al., 1998; Zhu et al., 1998), no $\kappa \mathrm{OR}-\mathrm{IR}$ was detected among MC innervation.

\section{Adrenergic receptors}

Both the peptidergic $\mathrm{C}$-fiber and $\mathrm{A} \alpha \beta$-fiber innervations of MCs express adrenergic receptors, which may play a potent antinociceptive role (Reddy et al., 1980; Yaksh, 1985; Mendez et al., 1990; Eisenach et al., 1995; O'Halloran and Perl, 1997; Fairbanks and Wilcox, 1999b). In addition, consistent with our finding that adrenergic receptors are colocalized on innervation with opioid receptors, increasing evidence indicates a synergistic interaction between $\alpha 2$-adrenergic and opioid receptors (Ossipov et al., 1990; Roerig et al., 1992; Stone et al., 1997; Fairbanks and Wilcox, 1999a; Fairbanks et al., 1999; Herrero and Solano, 1999).

\section{Vanilloid-like receptor}

Recently, Caterina et al. (1999) showed that VRL1 is sensitive solely to high-temperature noxious stimuli $\left(>53^{\circ} \mathrm{C}\right)$. Consistent with our detection of VRL1-IR on the A $\alpha \beta$ endings, Caterina et al. (1999) showed that VRL1 was located on medium to large neurons of rat DRGs.

\section{VR1-positive C-fiber innervation}

VR1-IR expression on nonpeptidergic C-fiber innervation to MCs agrees with observations in rats that VR1 is located on small to medium DRG neurons that usually lack CGRP (Guo et al., 1999). These neurons project to lamina I and the inner layer of lamina II, which are both implicated in central connectivity related to nociception. Unlike other innervation to the MCs, VR1 innervation lacked immunolabeling for P2X2, P2X3, 2 A, and $\alpha 2 \mathrm{C}$ adrenergic receptors. Labeling for $\mu \mathrm{OR}$ and $\delta \mathrm{OR}$ was not certain. However, immunolabeling for one or another of these channels or receptors was coexpressed on VR1-positive epidermal innervation, indicating that the immunochemical and presumably functional properties of MC and epidermal VR1positive innervation may be different. VR1-positive MC innervation did coexpress IR for NOCI and P2X1. Interestingly, Minami et al. (2000) recently showed that capsaicin-sensitive primary afferents are involved in tactile allodynia induced by nociceptin-orphanin FQ. Also, Petruska et al. (2000) found that P2X1-IR in rat DRGs was generally restricted to small neurons lacking NF-IR and CGRP-IR. Their results indicate that these neurons may be the same population that expresses high levels of VR1 mRNA (Michael and Priestley, 1999).

\section{Functional significance}

With their discoveries of unmyelinated contributions to MCs, Cauna (1956) and Johansson et al. (1999) speculated that MCs may also have a nociceptive role in addition to low-threshold mechanoreceptive functions. Consistent with that hypothesis, our results confirm not only the presence of a peptidergic C-fiber innervation to MCs but also another type of $\mathrm{C}$-fiber innervation that is nonpeptidergic and VR1-positive. Our results also show that the $\mathrm{A} \alpha \beta$-fiber and peptidergic $\mathrm{C}$-fiber innervations both have numerous immunochemical features implicated in nociception. In contrast, Merkel endings that are also supplied by A $\alpha \beta$-fibers lack these implicated nociceptive properties. Thus, MCs in monkey digital skin appear to be multiafferented polymodal receptor organs that may include nociceptive capability.

The normal purpose of these nociceptive characteristics remains to be elucidated. However, these characteristics suggest that $\mathrm{MC}$ innervation, under pathological conditions, may be involved in mechanical allodynia, which is purportedly mediated through $\mathrm{A} \alpha \beta$ low-threshold mechanoreceptive innervation (Campbell et al., 1988; Torebjörk et al., 1992; Neumann et al., 1996). Altered skin conditions such as inflammation can change the physiological endogenous environment by increasing extracellular ATP, which could potentiate the responses of MCs to low-threshold stimuli by changing their adaptation rate. Interestingly, $\mathrm{Na}$ et al. (1993) showed that dorsal root fibers with rapidly adapting-like properties in a rat model of neuropathic pain developed low and irregular discharges during steady indentation of the skin. The close affiliation of peptidergic $\mathrm{C}$-fiber innervation to NK1-positive $\mathrm{A} \alpha \beta$-fiber innervation suggests that these $\mathrm{C}$-fibers may be able to modulate the sensory response characteristics of $\mathrm{A} \alpha \beta$-fibers directly at their peripheral endings. Alternatively, the absence of both the peptidergic $\mathrm{C}$ - and $\mathrm{A} \alpha \beta$-fiber innervation in some MCs suggests that the peptidergic $\mathrm{C}$-fiber innervation may have a trophic impact on the A $\alpha \beta$ innervation. These possibilities are currently being explored.

\section{REFERENCES}

Arvidsson U, Dado RJ, Riedl M, Lee J-H, Law P-Y, Loh HH, Elde R, Wessendorf MW (1995a) Delta-opioid receptor immunoreactivity: 
distribution in brainstem and spinal cord, and relationship to biogenic amines and enkephalin. J Neurosci 15:1215-1235.

Arvidsson U, Riedl M, Chakrabarti S, Lee J-H, Nakano AH, Dado RJ, Loh HH, Law P-Y, Wessendorf MW, Elde R (1995b) Distribution and targeting of a $\mu$-opioid receptor (MOR1) in brain and spinal cord. J Neurosci 15:3328-3341.

Arvidsson U, Riedl M, Chakrabarti S, Vulchanova L, Lee J-H, Nakano AH, Lin X, Loh HH, Law P-Y, Wessendorf MW, Elde R (1995c) The $\kappa$-opioid receptor (KOR1) is primarily postsynaptic: combined immunohistochemical localization of the receptor and endogenous opioids. Proc Natl Acad Sci USA 92:5062-5066.

Ballet S, Mauborgne A, Benoliel J-J, Bourgoin S, Hamon M, Cesselin F, Collin E (1998) Polyarthritis-associated changes in the opioid control of spinal CGRP release in the rat. Brain Res 796:198-208.

Björklund H, Dalsgaard CJ, Jonsson C-E, Hermasson A (1986) Sensory autonomic innervation of non-hairy skin and hairy human skin. Cell Tissue Res 243:51-57.

Blake DT, Johnson KO, Hsiao SS (1997a) Monkey cutaneous SAI and RA responses to raised and depressed scanned patterns: effects of width, height, orientation, and a raised surround. J Neurophysiol 78:2503-2517.

Blake DT, Hsiao SS, Johnson KO (1997b) Neural coding mechanisms in tactile pattern recognition: the relative contributions of slowly and rapidly adapting mechanoreceptors to perceived roughness. J Neurosci 17:7480-7489.

Bland-Ward PA, Humphrey PP (1997) Acute nociception mediated by hindpaw $\mathrm{P} 2 \mathrm{X}$ receptor activation in the rat. $\mathrm{Br} \mathrm{J}$ Pharmacol 122:365-371.

Bleehen T, Keele CA (1977) Observations on the algogenic actions of adenosine compounds on the human blister base preparation. Pain 3:367-377.

Campbell JN, Raja SN, Meyer RA, Mackinnon SE (1988) Myelinated afferents signal the hyperalgesia associated with nerve injury. Pain 32:89-94.

Carrington WA, Lynch RM, Moore EDW, Isenberg G, Fogarty KE, Fay FS (1995) Superresolution three-dimensional images of fluorescence in cells with minimal light exposure. Science 268:1483-1487.

Caterina MJ, Schumacher MA, Tominaga M, Rosen TA, Levine JD, Julius D (1997) The capsaicin receptor: a heat-activated ion channel in the pain pathway. Nature 389:816-824

Caterina MJ, Rosen TA, Tominaga M, Brake AJ, Julius D (1999) A capsaicin-receptor homologue with high threshold for noxious heat. Nature 398:436-441.

Caterina MJ, Leffler A, Malmberg AB, Martin WJ, Trafton J, PetersenZeitz KR, Koltzenburg M, Basbaum AI, Julius D (2000) Impaired nociception and pain sensation in mice lacking the capsaicin receptor. Science 288:306-313.

Cauna N (1956) Nerve supply and nerve endings in Meissner's corpuscles. Am J Anat 99:315-327.

Coggeshall RE, Zhou S, Carlton SM (1997) Opioid receptors on peripheral sensory axons. Brain Res 764:126-132.

Cook SP, Vulchanova L, Hargreaves M, Elde R, McCleskey EW (1997) Distinct ATP receptors on pain-sensing and stretch-sensing neurons. Nature 387:505-508.

Dalsgaard CJ, Jonsson C-E, Hökfelt T, Cuello AC (1983) Localization of substance P-immunoreactive nerve fibers in the human digital skin. Experientia 39:1018-1020.

Dalsgaard CJ, Jernbeck J, Stains W, Kjartansson J, Haegerstrand A, Hökfelt T, Brodin E, Cuello AC, Brown JC (1989) Calcitonin generelated peptide like immunoreactivity in nerve fibers in the human skin: relation to fibers containing substance $\mathrm{P}$-, somatostatin- and vasoactive intestinal polypeptide-like immunoreactivity. Histochemistry 91:35-38.

Dogiel AS (1892) Die Nervenendigunden in Meissnerschen Tasktköperen. Monthly Int J Anat Physiol 9:76-85.

Duggan AW, Hope PJ, Jarrott B, Schaible HG, Fleetwood-Walker SM (1990) Release, spread and persistence of immunoreactive neurokinin A in the dorsal horn of the cat following noxious cutaneous stimulation. Studies with antibody microprobes. Neuroscience 35:195-202.

Eisenach JC, DuPen S, Dubios M, Miguel R, Allin D (1995) Epidural clonidine analgesia for intractable cancer pain. Pain 61:391-399.

Fairbanks CA, Wilcox GL (1999a) Spinal antinociceptive synergism between morphine and clonidine persists in mice made acutely or chronically tolerant to morphine. J Pharmacol Exp Ther 288:1408-1417.

Fairbanks CA, Wilcox GL (1999b) Moxonidine, a selective $\alpha 2$ adrenergic and imidazoline receptor agonist, produces spinal antinociception in mice. J Pharmacol Exp Ther 290:403-412.

Fairbanks CA, Posthumus IJ, Kitto KF, Stone LS, Wilcox GL (1999) Moxonidine, a selective imidazoline $/ \alpha 2$ adrenergic receptor agonist, synergizes with morphine and deltrophin II to inhibit substance P-induced behavior in mice. Pain 84:13-20.

Gether U, Johansen TE, Snider RM, Lowe JA, Emonds-Alt X, Yokota Y, Nakanishi S, Schwartz TW (1993) Binding epitopes for peptide and non-peptide ligands on the NK1 (substance P) receptor. Regul Pept 46:49-58

Guinard D, Usson Y, Guillermet C, Saxod R (2000) PS-100 and NF
70-200 double immunolabeling for human digital skin Meissner corpuscle 3D imaging. J Histochem Cytochem 48:295-302.

Guo A, Vulchanova L, Wang J, Li X, Elde R (1999) Immunocytochemical localization of the vanilloid receptor 1 (VR1): relationship to europeptides, the P2X3 purinoceptor and IB4 binding sites. Eur J Neurosci 11:946-958.

Halata Z (1975) The mechanoreceptors of the mammalian skin. Ultrastructure and morphological classification. In: Advances in anatomy, embryology, and cell biology, Vol 50 (Brodal A, Hild W, van Limborgh J, Ortmann R, Schlieber TH, Töndury G, Wolff E, eds), pp 7-75. Berlin: Springer.

Hamilton SG, Warburton J, Bhattacharjee A, Ward J, McMahon SB (2000) ATP in human skin elicits a dose-related pain response which is potentiated under conditions of hyperalgesia. Brain 123:1238-1246.

Herrero JF, Solano RE (1999) The antinociceptive effect of the muopioid fentanyl is reduced in the presence of the alpha2-adrenergic antagonist idazoxan in inflammation. Brain Res 840:106-114.

Ishida-Yamamoto A, Senba E, Tohyama M (1988) Calcitonin generelated peptide- and substance P-immunoreactive nerve fibers in Meissner's corpuscles of rats: an immunohistochemical analysis. Brain Res 453:362-366

Johansson O, Fantini F, Hu H (1999) Neuronal structural proteins, transmitters, transmitters enzymes and neuropeptides in human Meissner's corpuscles: a reappraisal using immunohistochemistry. Arch Dermatol Res 291:419-424.

Johansson RS (1978) Tactile sensibility in the human hand: receptive field characteristics of mechanoreceptive units in the glabrous skin area. J Physiol (Lond) 281:101-123.

Knibestöl M, Vallbo AB (1970) Single unit analysis of mechanoreceptor activity from human glabrous skin. Acta Physiol Scand 80:178-195.

Kruger L (1988) Morphological features of thin sensory afferent fibers: a new interpretation of "nociceptor" function. Prog Brain Res 74:253-257.

Kruger L, Silverman JD, Mantyh PW, Sternini C, Brecha NC (1989) Peripheral patterns of calcitonin-gene-related peptide general somatic sensory innervation: cutaneous and deep terminations. J Comp Neurol 280:291-302.

Lewis C, Neldhart S, Holy C, North CA, Buell G, Surprenant A (1995) Coexpression of $\mathrm{P} 2 \mathrm{X} 2$ and $\mathrm{P} 2 \mathrm{X} 3$ receptor subunits can account for ATP-gated currents in sensory neurons. Nature 377:432-435.

Lindblom U (1965) Properties of touch receptors in distal glabrous skin of the monkey. J Neurophysiol 28:966-985.

Lindh B, Lundberg JM, Hökfelt T (1989) NPY-, galanin-, VIP/PHI-, CGRP- and substance P-immunoreactive neuronal subpopulations in cat autonomic and sensory ganglia and their projections. Cell Tissue Res 256:259-273.

Maggi CA (1995) Tachykinins and calcitonin gene-related peptide (CGRP) as co-transmitters released from peripheral endings of sensory nerves. Prog Neurobiol 45:1-98.

McCarthy PW, Lawson SN (1990) Cell type and conduction velocity of rat primary sensory neurons with calcitonin gene-related peptide-like immunoreactivity. Neuroscience 34:623-632.

Mendez R, Eisenach JC, Kashtan K (1990) Epidural clonidine analgesia after cesarean section. Anesthsiology 73:848-852.

Michael GJ, Priestley JV (1999) Differential expression of the mRNA for the vanilloid receptor subtype $I$ in cells of the adult rat dorsal root and nodose ganglia and its downregulation by axotomy. J Neurosci 19:1844-1854.

Minami T, Okuda-Ashitaka E, Mori H, Sakimura K, Watanabe M, Mishina M, Ito S (2000) Characterization of nociceptin/orphanin FQinduced pain responses in conscious mice: neonatal capsaicin treatment and $N$-methyl-D-aspartate receptor Glur $\epsilon$ subunit knockout mice. Neuroscience 97:133-142.

Munger BL, Ide C (1988) The structure and function of cutaneous sensory receptors. Arch Histol Cytol 51:1-34.

$\mathrm{Na}$ HS, Leem JW, Chung JM (1993) Abnormalities of mechanoreceptors in a rat model of neuropathic pain: possible involvement in mediating mechanical allodynia. J Neurophysiol 70:522-528.

Neumann S, Doubell TP, Leslie T, Woolf CJ (1996) Inflammatory pain hypersensitivity mediated by phenotypic switch in myelinated primary sensory neurons. Nature 384:360-364.

O'Halloran KD, Perl ER (1997) Effects of partial nerve injury on the responses of c-fiber polymodal nociceptors to adrenergic agonists. Brain Res 759:233-240.

Oku R, Satoh M, Fujii N, Otaka A, Yajima H, Takagi H (1987) Calcitonin gene-related peptide promotes mechanical nociception by potentiating release of substance $\mathrm{P}$ from the spinal dorsal horn in rats. Brain Res 403:350-354.

Ossipov M, Lozito R, Messineo E, Green J, Harris S, Lloyd P (1990) Spinal antinociceptive synergy between clonidine and morphine, U69593, and DPDPE: Isobolographic analysis. Life Sci 47:PL71-PL76.

Petruska JC, Cooper BY, Gu JG, Rau KK, Johnson RD (2000) Distribution of $\mathrm{P} 2 \mathrm{X} 1, \mathrm{P} 2 \mathrm{X} 2$, and $\mathrm{P} 2 \mathrm{X} 3$ receptor subunits in rat primary afferents: relation to population markers and specific cell types. J Chem Neuroanat 20:141-162. 
Proske U, Gregory JE, Iggo A (1998) Sensory receptors in monotremes. Philos Trans R Soc Lond [Biol] 353:1187-1198.

Pubols LM, Pubols BH, Munger BL (1971) Functional properties of mechanoreceptors in glabrous skin of the raccoon's forepaw. Exp Neurol 31:165-182.

Reddy SVR, Maderdrut JL, Yaksh TL (1980) Spinal cord pharmacology of adrenergic agonist-mediated antinociception. J Pharmacol Exp Ther 213:525-533.

Rice FL, Rasmusson DD (2000) Innervation of the digit on the forepaw of the raccoon. J Comp Neurol 417:467-490.

Rice FL, Fundin BT, Arvidsson J, Aldskogius H, Johansson O (1997) Comprehensive immunofluorescence and lectin binding analysis of vibrissal follicle-sinus complex innervation in the mystacial pad of the rat. J Comp Neurol 385:149-184.

Riedl M, Shuster S, Vulchanova L, Wang J, Loh HH, Elde R (1996) Orphanin FQ/nociceptin-immunoreactive nerve fibers parallel those containing endogenous opioids in rat spinal cord. NeuroReport 31:1369-1372.

Roerig S, Lei S, Kitto K, Hylden JLK, Wilcox GL (1992) Spinal interactions between opioid and noradrenergic agonists in mice: multiplicativity involves $\delta$ and $\alpha 2$ receptors. J Pharmacol Exp Ther 262:365-374.

Souslova V, Cesare P, Ding Y, Akopian AN, Stanfa L, Suzuki R, Carpenter K, Dickenson A, Boyce S, Hill R, Nebenius-Oosthuizen D, Smith AJH, Kidd EJ, Wood JN (2000) Warm-coding deficits and aberrant inflammatory pain in mice lacking $\mathrm{P} 2 \mathrm{X} 3$ receptors. Nature 407:1015-1017

Srinivasan MA, Whitehouse JM, LaMotte RH (1990) Tactile detection of slip: surface microgeometry and peripheral neural codes. J Neurophysiol 63:1323-1332.

Stein C (1995) The control of pain in peripheral tissue by opioids. N Engl J Med 332:1685-1690.

Stone LS, MacMillan LB, Kitto KF, Limbird LE, Wilcox GL (1997) The a2a-adrenergic receptor subtype mediates spinal analgesia evoked by a2-agonists and is necessary for spinal adrenergic-opioid synergy. J Neurosci 17:7157-7165.

Stone LS, Broberger C, Vulchanova L, Wilcox GL, Hökfelt T, Riedl M, Elde R (1998) Differential distribution of alpha2A and alpha2C adrenergic receptor immunoreactivity in the rat spinal cord. J Neurosci 18:5928-5937.

Talbot WH, Darian-Smith I, Kornhuber HH, Mountcastle VB (1968)
The sense of flutter-vibration: comparison of the human capacity with response patterns of mechanoreceptive afferents from the monkey hand. J Neurophysiol 31:301-334.

Tominaga M, Caterina MJ, Malmberg AB, Rosen TA, Gilbert H, Skinner K, Raumann BE, Basbaum AI, Julius D (1998) The cloned capsaicin receptor integrates multiple pain-producing stimuli. Neuron 21:531-543.

Torebjörk HE, Lundberg LER, LaMotte RH (1992) Central changes in processing of mechanoreceptive input in capsaicin-induced secondary hyperalgesia in humans. J Physiol (Lond) 448:765-780.

Tsuda M, Koizumi S, Kita A, Shigemoto Y, Ueno S, Inoue K (2000) Mechanical allodynia caused by intraplantar injection of $\mathrm{P} 2 \mathrm{X}$ receptor agonist in rats: involvement of heteromeric $\mathrm{P} 2 \mathrm{X} 2 / 3$ receptor signaling in capsaicin-insensitive primary afferent neurons. J Neurosc 20:RC-90(1-5)

Turnbull BG, Rasmusson DD (1986) Sensory innervation of the raccoon forepaw: 1. Receptor types in glabrous and hairy skin and deep tissue. Somatosens Res 4:43-62.

Urban L, Thompson SW, Fox AJ, Jeftinija S, Dray A (1995) Peptidergic afferents: physiological aspects. Prog Brain Res 104:255-269.

Vulchanova L, Arvidsson U, Riedl M, Wang J, Buell G, Surprenant A North RA, Elde R (1996) Differential distribution of two ATP-gated ion channels (P2X receptors) determined by immunocytochemistry. Proc Natl Acad Sci USA 93:8063-8067.

Yaksh TL (1985) Pharmacology of spinal adrenergic systems which modulate spinal nociceptive processing. Pharmacol Biochem Behav 22:845-858.

Zhang Q, Schaeffer M, Elde R, Stein C (1998) Effects of neurotoxins and hindpaw inflammation on opioid receptor immunoreactivities in dorsal root ganglia. Neuroscience 85:281-291.

Zhang X, Bao L, Arvidsson U, Elde R, Hökfelt T (1998) Localization and regulation of the delta-opioid receptor in dorsal root ganglia and spinal cord of the rat and monkey: evidence for association with the membrane of large dense-core vesicles. Neuroscience 82:1225-1242.

Zhou L, Zhang Q, Stein C, Schafer M (1998) Contribution of opioid receptors on primary afferent versus sympathetic neurons to peripheral opioid analgesia. J Pharmacol Exp Ther 286:1000-1006.

Zhu Y, Hsu MS, Pintar JE (1998) Developmental expression of the mu, kappa and delta opioid receptor mRNAs in mouse. J Neurosci 18:25382549. 